\title{
O INHANDUVÁ (PROSOPIS AFFINIS SPRENG.) NO RIO GRANDE DO SUL. 1 - EMBASAMENTO FITOGEOGRÁFICO E PENDÊNCIAS TERMINOLÓGICAS.
}

\author{
JOSÉ NEWTON CARDOSO MARCHIORI ${ }^{1}$ FABIANO DA SILVA ALVES ${ }^{2}$
}

\section{RESUMO}

São discutidas questões fitogeográficas e terminológicas, constantes na literatura sobre o inhanduvá (Prosopis affinis Spreng., Fabaceae) no Rio Grande do Sul.

Palavras-chave: Prosopis affinis, Fitogeografia, Rio Grande do Sul.

\section{SUMMARY}

[Prosopis affinis Spreng. in Rio Grande do Sul state, Brazil. 1 - Phytogeographic basement and nomenclatural questions].

Phytogeographic and terminological questions found in the literature about Prosopis affinis Spreng. (Fabaceae) in Rio Grande do Sul state (Brazil) are discussed.

Key words: Prosopis affinis, Phytogeography, Rio Grande do Sul state.

\section{INTRODUÇÃO}

O inhanduvá (Prosopis affinis Spreng.), juntamente com o algarrobo ${ }^{3}, o$ espinilho ${ }^{4}$, a cinacina $^{5}$, o quebracho-branco ${ }^{6}$, o pau-ferro ${ }^{7}$, as sombras-de-touro $^{8}$ e as aroeiras ${ }^{9}$, integram um contingente singular na flora arbórea do Rio Grande do Sul: o dos elementos chaquenhos (sensu Waechter, 2002), interpretados por Balduino Rambo (1956), em definição lapidar,

1 Engenheiro Florestal, Dr., Professor Titular do Departamento de Ciências Florestais, UFSM. Bolsista de Produtividade em Pesquisa (CNPq - Brasil).

2 Biólogo, MSc., doutorando do Programa de Pós-Graduação em Engenharia Florestal - UFSM. Professor da Universidade da Região da Campanha - URCAMP (Alegrete, RS).

3 Prosopis nigra (Griseb.) Hieron. (Fabaceae).

4 Vachellia caven (Mol.) Seigler \& Ebinger; o binômio Acacia caven (Mol.) Mol., de uso freqüente na literatura botânica do século 20, acabou reduzido à sinonímia.

5 Parkinsonia aculeata L. (Fabaceae).

6 Aspidosperma quebrachoblanco Schltdl. (Apocynaceae).

7 Myracrodruon balansae (Engl.) Santin (sinônimo: Astronium balansae Engler).

8 Nome comum atribuído a duas espécies de Santalaceae: Acanthosyris spinescens (Mart. \& Eichl.) Griseb. e Jodina rhombifolia (Hook. \& Arn.) Reissek.

9 Nome popular atribuído a várias espécies de Lithraea e Schinus (Anacardiaceae). como "as últimas ondas do pampa argentino, jogadas na Campanha riograndense"10. Desta lista, o inhanduvá ${ }^{11}$ distingue-se por ter madeira muito dura, pesada e resistente à deterioração, à semelhança do pau-ferro anteriormente citado e de outras Anacardiáceas do Chaco propriamente dito ${ }^{12}$, pertencentes ao gênero Schinopsis (quebrachos-vermelhos).

Produtor de madeira reconhecidamente valiosa ao homem do campo, sobretudo para usos em contato com o solo, o inhanduvá também era a preferida pelos gaúchos primitivos para a confecção de freios, segundo registro de Nicolau Dreys ${ }^{13}$.

10 Rambo, B. A fisionomia do Rio Grande do Sul. Porto Alegre: Livraria Selbach, 1956. p. 144.

11 O inhanduvá pertence à família Fabaceae; a literatura mais antiga considera o gênero entre as Mimosaceae ou nas Leguminosae Mimosoideae.

12 Situado ao norte da província do Espinal, a província do Chaco estende-se pelo centro-norte da Argentina, oeste do Paraguai e sudoeste da Bolívia.

13 "O freio he feito de páo duro, ordinariamente de nhanduai, embutido em cada uma de suas pontas hum pedaço de chiffre cortado segundo o seu comprimento." (Dreys, N. Noticia descriptiva da Provincia do RioGrande de S. Pedro do Sul. Rio de Janeiro: Typ. Imp. e Const. de J. Villeneuve e Comp., 1839. p. 197). 
Por seu reconhecido valor, a espécie é uma das mais evocadas na literatura gauchesca, desde meados do século XIX. No poema "Santos Vega" ${ }^{14}$, por exemplo, Hilário Ascasubi descreve a excelência da paliçada de ñandubay construída em torno das casas de uma estância, como proteção aos ataques dos índios ${ }^{15}$. Por sua "duração ilimitada", esta madeira sempre foi preferida para palanques e currais, segundo Richard Seymour, importante cronista do povoamento no sudeste de Córdoba (Argentina) ${ }^{16}$. Também no Rio Grande do Sul se pode admirar, ainda praticamente intacto, um palanque remanescente de extinta estância missioneira (século XVIII), presenteado a Joaquim Francisco de Assis Brasil na primeira década do século XX e por ele plantado frente ao "Galpão das Vacas", na Granja de Pedras Altas, arredores da cidade gaúcha homônima.

Apesar de sua pequena área de ocorrência natural, limitada ao canto sudoeste do Estado, o inhanduvá sempre aparece em termos elogiosos na literatura sul-rio-grandense. João Simões Lopes Neto, por exemplo, valeu-se da dureza de sua madeira, em $O$ Anjo da Vitória ${ }^{17}$, para caracterizar a vigorosa carga de cavalaria ${ }^{18}$

14 Longo poema gauchesco, editado originalmente em Paris, no ano de 1872.

15 "Después de eso, uma estacada / de ñandubay de mi flor, / tan pareja y tan fornida / que el poste más delgadón / no lo arrastraba una cuadra / el pingo más cinchador" (Ascasubi, H. Santos Vega el payador. In: Poesia gauchesca. México: Fondo de Cultura Económica, 1984. v. 1. p. 327-328).

16 "El ñandubay es muy duro y de duración ilimitada, pues conócense corrales de postes de este árbol, en excelentes condiciones y que se sabe cuentan con más de cien años de existência" (Seymour, R.A. Un poblador de las Pampas. Córdoba: Impressos M.C., 1995. p. 57).

17 Integrante de "Contos Gauchescos", obra prima da literatura sul-rio-grandense, editada, originalmente, em 1912.

18 "Firme nos estribos, com o boné levantado sobre o cocuruto da cabeça, a espada apontando como um dedo, faiscando, o velhito ponteou aquela tormenta, que se despenhou pelo lançante abaixo e afundou-se e entranhou-se na massa cerrada do inimigo, como uma cu- protagonizada pelo Barão de Cerro Largo (José de Abreu) na Batalha do Passo do Rosário ${ }^{19}$. Na Argentina e Uruguai, onde a espécie é mais conhecida e apresenta ampla área de ocorrência, o termo inhanduvá chega a ser usado como metáfora para descrever o valor, resistência ou vigor do homem do campo ${ }^{20}$.

Reconhecido por sua importância econômica, o inhanduvá, mesmo assim, raramente é cultivado no Rio Grande do Sul. Mais preocupante, todavia, é o resultado da ação antrópica sobre os fragmentos remanescentes de vegetação nativa, visto que o processo tende a desfavorecer a espécie em benefício do espinilho (Vachellia caven), seja por eventuais queimadas ou pela predação de brotações pelo gado.

O "Parque Estadual do Espinilho", criado em $12 / 3 / 1975$, visa, justamente, a preservar o fragmento mais representativo desta vegetação singular no sul do Brasil. Localizado nas proximidades do núcleo urbano de Barra do Quaraî ${ }^{21}$, sua área original, de aproximadamente 276 ha, foi ampliada para $1.617,14$ ha em $28 / 2 / 2002^{22}$.

No presente trabalho, o primeiro de uma série dedicada a investigar a distribuição geográfica do inhanduvá no Rio Grande do Sul, buscou-se estabelecer um embasamento fitogeográfico, bem como discutir alguns pontos controvertidos, constantes na literatura, sobre o mesmo tema.

nha de inhanduvai abrindo em dois um moirão grosso de guajuvira"(Simões Lopes Neto, J. Contos Gauchescos e Lendas do Sul. Porto Alegre: Editora Globo, 1957. p. 202).

19 Batalha de Ituzaingó, para os autores castelhanos.

20 "Cuando en el litoral se quiere ponderar la reciedumbre y el aguante de un paisano, se lo compara al ñandubay"(Biloni, J.S. Arboles autoctonos argentinos. Buenos Aires: Tipográfica Editora Argentina, 1990. p. 159).

21 Decreto $^{\circ}{ }^{2} 23.798$, do Governo do Estado do Rio Grande do Sul.

22 Decreto $^{\circ} 41.440$, do Governo do Estado do Rio Grande do Sul. 


\section{EMBASAMENTO FITOGEOGRÁFICO}

A literatura fitogeográfica de base florística é unânime ao reconhecer o inhanduvá como uma das espécies mais importantes da vegetação autóctone na metade sul de Corrientes - vizinha a Barra do Quaraí, separada apenas pelo rio Uruguai -, bem como no noroeste e centro de Entre Rios, regiões que, segundo Cabrera \& Willink (1973), compõem o Distrito del Ñandubay ${ }^{23}$, integrante da Província del Espinal ${ }^{24}$ e Domínio Chaquenho. Em obras mais antigas, a mesma vegetação é freqüentemente definida como "Parque Mesopotâmico" (Parodi, 1945; Tortorelli, 1956; Dimitri, 1979; Mutarelli, 1979), uma referência ao território argentino compreendido entre os rios Paraná e Uruguai.

Para a "comunidade clímax" deste distrito, Cabrera $(1971,1994)$ relaciona, além do inhanduvá, árvore que lhe dá nome, as seguintes espécies arbóreas: algarrobo (Prosopis nigra), espinilho (Vachellia caven), taleira (Celtis ehrenbergiana), quebracho-branco (Aspidosperma quebrachoblanco), jataí (Butia yatay), chal-chal (Allophyllus edulis), sombrade-touro (Jodina rhombifolia), coentrilho (Zanthoxylum fagara), duas "coronilhas" (Scutia buxifolia e Sideroxylon obtusifolium), além de outras três espécies ${ }^{25}$ não citadas para a flora sul-rio-grandense $\mathrm{e}^{26}$.

Em sua vasta área de ocorrência, o Distrito do Inhanduvá abrange distintas associações e comunidades edáficas, diferenciadas pela contribuição de uma ou poucas espécies: é o caso

23 Inhanduvá, em português.

${ }^{24}$ Espinhal, em bom português. Embora não dicionarizada, a palavra já é bem conhecida e encontradiça na literatura sul-rio-grandense, motivo pelo qual será grafada em itálico, para indicar sua origem estrangeira.

25 São elas: Geoffroea decorticans (chañar), Tabebuia nodosa (totoratay) e Trithrinax campestris (caranday).

26 Os binômios latinos arrolados por CABRERA (1971) e atualmente reduzidos à sinonímia, foram substituídos pelos nomes válidos correspondentes. do Algarrobal, agrupamento de algarrobos e inhanduvás (Chebataroff, 1980a, 1980b; Paz \& Bassagoda, 2002; Burkart, 1957); do Ñandubaysal, marcado fisionômica e estruturalmente pelo inhanduvá (Burkart, 1957; Paz \& Bassagoda, 2002); do Espinillar ou Espinillal, uma associação de espinilhos (Vachellia caven); do Talar, associação de taleiras (Celtis ehrenbergiana); dos Palmares de Butia yatay, muito conspícuos em Entre Rios e Corrientes, pelo porte esbelto da espécie homônima ${ }^{27}$; dos Palmares de Trithrinax campestris, muito característicos no centro-oeste de Entre Rios, compondo palmares ou misturando-se com o bosque (Cabrera, 1971); das Estepes de Elionurus muticus e Panicum racemosum, vinculados a paleodunas (Cabrera, 1971); dos campos de Andropogon lateralis ${ }^{28}$, típicos de solos arenosos úmidos; das pradarias de Paspalum e Axonopus, vinculadas a solos levemente ácidos e úmidos; e do Chircal, baseado em Asteráceas ditas "chircas", como Eupatorium buniifolium e Vernonia nitidula (Paz \& Bassagoda, 2002).

Além do distrito do Inhanduvá acima considerado, a Província do Espinal ainda compreende os distritos do Algarrobo e do Caldén, descrevendo, ao longo de sua vasta área de ocorrência, um grande arco irregular no território argentino, desde Corrientes e Entre Rios até o litoral atlântico, ao sul da província de Buenos Aires, passando pela região central de Santa Fé, Córdoba, São Luís e La Pampa ${ }^{29}$.

Integrante do Domínio Chaquenho, o Espinal encontra-se entre as províncias do Chaco e Pampeana, distinguindo-se da primeira, situa-

27 Cabrera (1971) informa que os palmares de Butia yatay vinculam-se a solos arenosos, com subsolo rochoso a pouca profundidade.

28 Paja colorada, segundo Cabrera (1971).

29 Como visto anteriormente, o Distrito del Ñandubay constitui o trecho mais a nordeste deste arco, seguindo-se o Distrito del Algarrobo, marcado pelo predomínio de Prosopis alba e P. nigra, e o Distrito del Caldén, uma referência ao nome popular de Prosopis caldenia. 


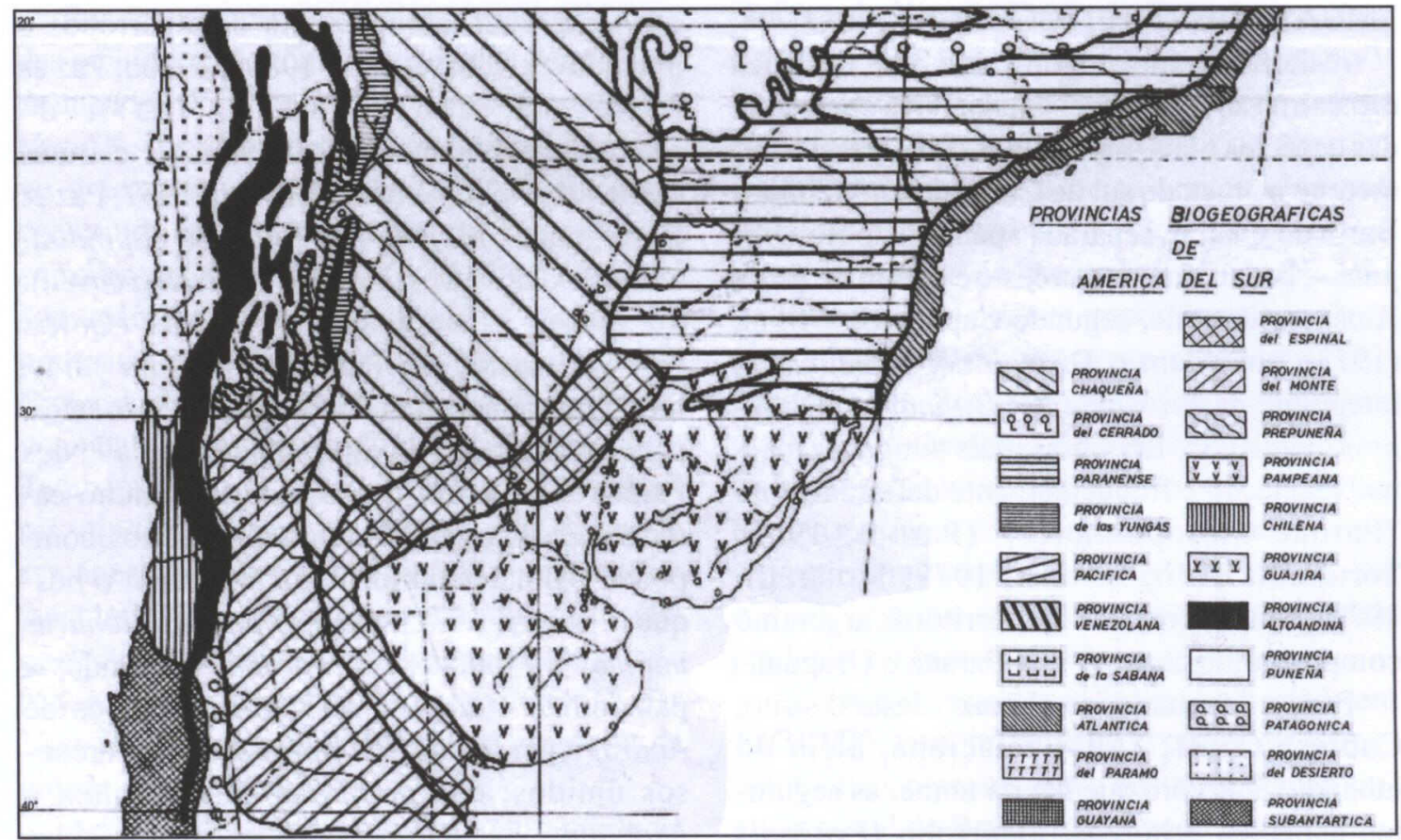

FIGURA 1 - Províncias biogeográficas da América do Sul subtropical, de acordo com Cabrera \& Willink (1980).

da ao norte ${ }^{30}$, sobretudo pela ausência do gênero Schinopsis ${ }^{31}$ em sua composição florística; o Pampa, por sua vez, difere do Espinal pela ausência de elementos arbóreos em sua estrutura. Na literatura fitogeográfica, destacam-se, como sinônimos para a Província do Espinal, as seguintes denominações: Bosque Pampeano ${ }^{32}$ (Parodi, 1945), Monte Periestépico (Frenguelli, 1941) e Subformación del Monte Oriental (Holmberg, 1898).

30 Não se pode confundir a província Chaquenha com Domínio Chaquenho; como unidade fitogeográfica mais ampla, o referido Domínio abrange as províncias Chaquenha (propriamente dita), do Espinal, Pampeana, Prepuneña e do Monte, entre outras.

31 Gênero de Anacardiaceae com, pelo menos, três espécies no Chaco argentino: Schinopsis balansae Engler (quebracho colorado), Schinopsis lorentzii (Griseb.) Engler (quebracho santiagueño) e Schinopsis marginata Engler (orco quebracho).

32 Segundo o autor (Parodi, 1945), o Bosque Pampeano corresponde ao Distrito del Caldén (sensu Cabrera, 1971), extendendo-se do centro-norte da província de San Luís, até seu limite austral com o rio Colorado.
No mapa fitogeográfico fornecido por Cabrera \& Willink (1973), vê-se, com clareza, que o Espinal toca o Rio Grande do Sul na região de Barra do Quaraí, levando à interpretação do "Parque Espinilho" como mero prolongamento da referida unidade fitogeográfica, a leste do rio Uruguai; cabe salientar, todavia, que a extensão da mesma no território gaúcho não pode ser especulada a partir da carta argentina (Figura 1).

Sob embasamento distinto, o Parque Espinilho sul-rio-grandense foi definido como formação "Parque", integrante da "Região Fitoecológica da Estepe" (Veloso \& Góes-Filho, 1982), ou como "Região da Estepe Estacional Savanícola" (Leite, 1994, 1995). Para os objetivos do presente trabalho, entretanto, tais classificações carecem de interesse, seja pelo critério fitoecológico das mesmas, ou por suas evidentes fragilidades terminológicas.

Sobre o tema, merece comentário o reconhecimento da "Área do Sudoeste ou Parque do Espinilho" como "região fitogeográfica" distinta no Rio Grande do Sul. Proposta por Reitz et al. 


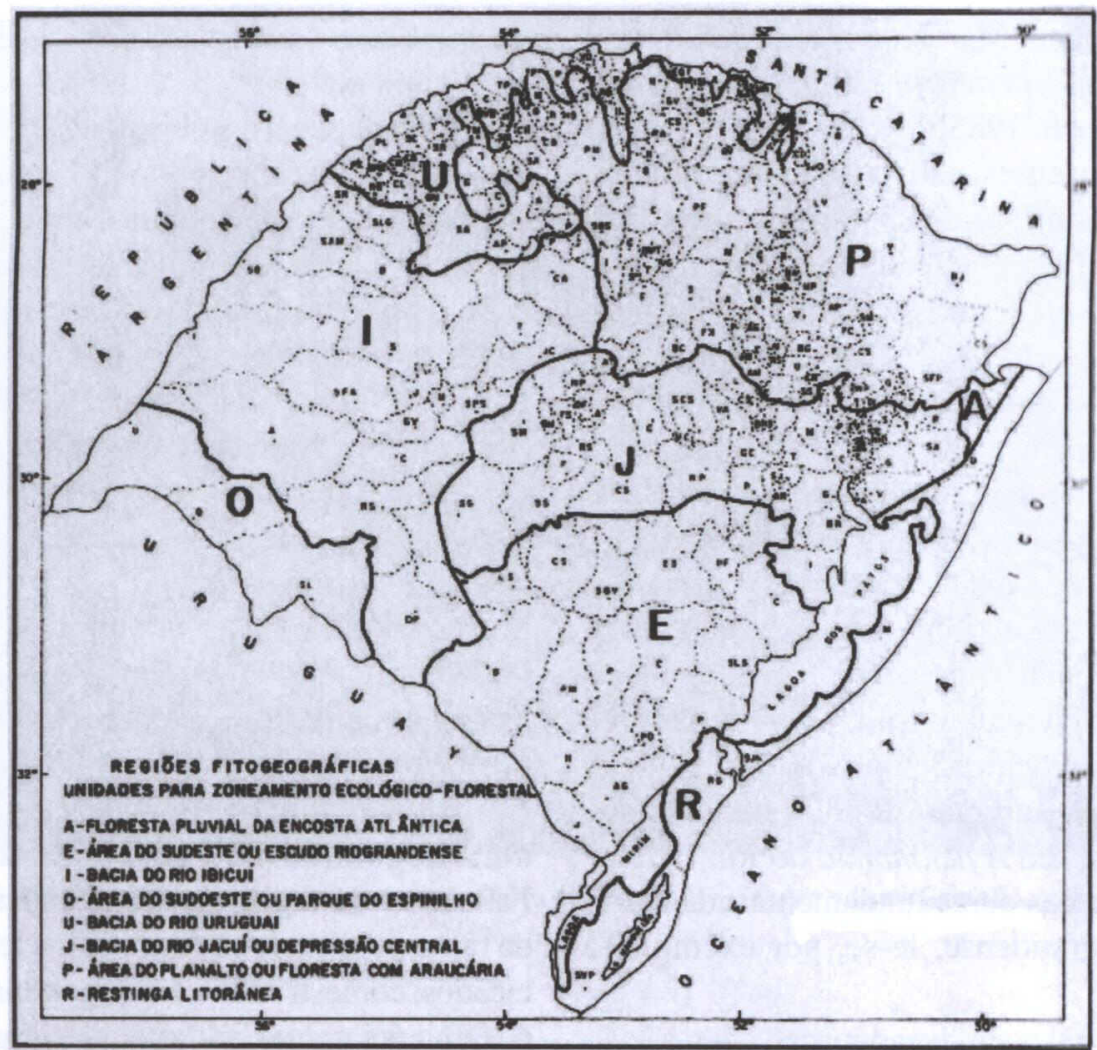

FIGURA 2 - Regiões fitogeográficas do Rio Grande do Sul, segundo Reitz et al. (1983).

(1983), a unidade abrange os municípios de Santana do Livramento e Quaraí, bem como a maior parte de Uruguaiana, município ao qual pertencia o distrito de Barra do Quaraí, atualmente emancipado ${ }^{33}$. De acordo com seus autores, a região compreende toda a bacia do rio Quaraí pelo lado brasileiro, bem como áreas adjacentes drenadas por tributários da margem esquerda do rio Ibicuí, estendendo-se, a noroeste, até as proximidades da foz deste rio com o Uruguai (Figura 2).

\section{PENDÊNCIAS TERMINOLÓGICAS}

A nomenclatura popular, usualmente variada, favorece inevitáveis confusões. Mesmo assim - e a bem da verdade -, as espécies arbóreas do "Parque do Espinilho" já eram corretamente

33 Definida por plebiscito, a emancipação de Barra do Quaraí data de 1995. identificadas pela população local em 1982, recebendo os mesmos nomes comuns, hoje consagrados na literatura.

Por ocasião de nossa primeira visita à Barra do Quaraí, feita na companhia de experiente proprietário rural da região como mateiro, tomou-se conhecimento da existência de duas espécies de Prosopis (inhanduvá e algarrobo), além do espinilho (atual Vachellia caven), do quebracho (Aspidosperma quebrachoblanco), da cina-cina (Parkinsonia aculeata), da sombra-de-touro (Acanthosyris spinescens) e da taleira (Celtis ehrenbergiana), entre outras plantas. O exame em laboratório do material coletado, junto com o apoio de bibliografia especializada, comprovou o acerto da diferenciação popular destas espécies, levando, na seqüência, à publicação de artigos com citações novas para a flora sul-rio-grandense, caso de Prosopis nigra (Marchiori et al., 1983), de Aspidosperma 
quebrachoblanco (Marchiori et al., 1985a), bem como de Tillandsia duratii e Tillandsia ixioides (Marchiori et al., 1985b).

Para os barrenses, não havia grande novidade: o Prosopis affinis dos botânicos ${ }^{34}$ era, simplesmente, o bem conhecido inhanduvá, ocorrendo o mesmo com Prosopis nigra, dito algarrobo, Vachellia caven (espinilho) e Aspidosperma quebrachoblanco (quebracho). Reconhecidamente valioso, o inhanduvá não era confundido com o algarrobo, produtor de madeira menos estimada, e muito menos com o espinilho, de boa madeira apenas para lenha e carvão. Estas três espécies, em suma, eram perfeitamente reconhecidas como entidades distintas pelo povo da região, em vivo contraste com o verificado em textos impressos.

Até mesmo Balduino Rambo não escapou de equívocos. Em A fisionomia do Rio Grande do $\mathrm{Sul}^{35}$, uma das obras fundamentais da literatura sul-rio-grandense, lê-se, por exemplo, à página 130:

"São principalmente duas espécies de leguminosas arborescentes, que determinam o aspecto curioso destes parques espinhosos e secos: o algarrobo (Prosopis algarobilla), e o inhanduvaí (Acacia farnesiana)".

Antes de entrar no ponto que interessa analisar, convém esclarecer que o binômio Prosopis algarobilla acabou reduzido, com o tempo, à sinonímia de Prosopis affinis, e que Acacia farnesiana (atual Vachellia farnesiana) é elemento raro na flora regional, ao contrário de

${ }^{34} \mathrm{Na}$ época, a literatura botânica referia-se à espécie como Prosopis algarobilla Griseb., binômio atualmente reduzido à sinonímia.

35 Com este nome, Balduíno Rambo publicou duas obras distintas: a primeira, de 1938, é texto bastante resumido e com escasso conteúdo fitogeográfico, especialmente para o quadrante sudoeste do Rio Grande do Sul, nada constando, por exemplo, a respeito do Parque Espinilho (Rambo, 1938); a segunda, é obra fundamental da literatura gaúcha e fonte primária para a terminologia fitogeográfica analisada no presente trabalho.
Acacia caven (atual Vachellia caven), o popular espinilho.

Digno de reparo, isto sim, é a designação de inhanduvaí, dada por Rambo a uma Acacia, posto que este nome popular aplica-se exclusivamente a Prosopis affinis, fato amplamente comprovado no restante da literatura botânica, bem como no linguajar regional. De origem guarani ( $\tilde{n} a n d u$, ema, o popular avestruz; ubai, comida, fruta), a palavra inhanduvaí entrou no português através do castelhano, à semelhança da planta à qual se aplica, que tem seu centro de distribuição nas planícies sedimentares da Mesopotâmia e Chaco argentino.

No tocante a "algarrobo", a palavra é tomada diretamente do castelhano, visto que, em português, corresponde à alfarrobeira ${ }^{36}$ Ceratonia siliqua L. -, nome dicionarizado para uma Leguminosae Caesalpinioideae (atual Fabaceae) da região do Mediterrâneo, cultivada tanto pela madeira como pelos legumes adocicados, comestíveis ${ }^{37}$. Na Argentina e Uruguai, o termo foi apropriado para designar quase todas as espécies do gênero Prosopis: Prosopis alba (algarrobo blanco), Prosopis chilensis (algarrobo do Chile), Prosopis flexuosa (algarrobo dulce), Prosopis nigra (algarrobo negro), Prosopis torquata (albarrobo chico) e Prosopis ruscifolia (algarrobo blanco, algarrobo de hoja grande), entre outras ${ }^{38}$. No caso do inhanduvá (ñandubay, em espanhol), o termo popular algarobillo é menos usual na literatura argentina, apesar de sua latinização constar num epíteto específico - Prosopis algarobilla Griseb. -, binômio reconhecido, atualmente, como sinônimo de Prosopis affinis Spreng.

36 Houaiss, A., Villar, M. de S. Dicionário Houaiss da Língua Portuguesa. Rio de Janeiro: Objetiva, 2001. p. 151.

37 Na região do Chaco, por exemplo, os algarrobos são valorizados como "verdadeiros graneros del pobre" (Demaio, P. et al. Árboles nativos del centro de Argentina. Buenos Aires, L.O.L.A., 2002. p. 113).

38 Para o leitor interessado, sugere-se a consulta de Demaio et al (2002). 


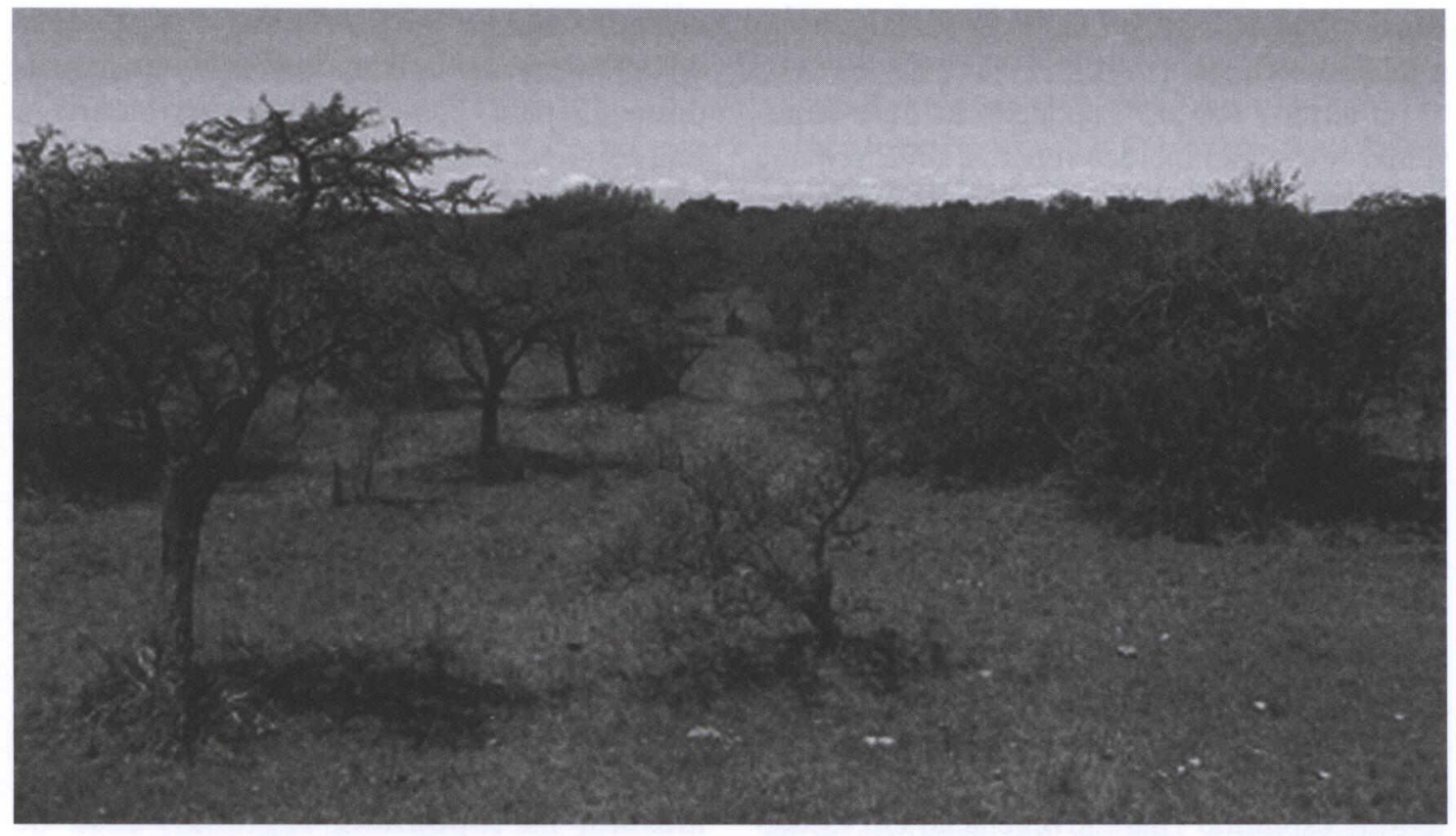

FIGURA 3 - Aspecto geral do Parque de Inhanduvá (Barra do Quaraí, RS). Notar a dominância fisionômica de Prosopis affinis Spreng.

A palavra inhanduvaí, aplicada a uma Acacia (atual Vachellia), aparece repetidas vezes no texto de Balduíno Rambo, sempre em equivocada referência ao bem conhecido espinilho (Vachellia caven). É deste modo que o autor informa ser esta a espécie "mais espalhada" das duas no Estado ${ }^{39}$, distribuindo-se a oeste da "linha que liga Bagé, Cruz Alta, Barra do Ijuí, rio Uruguai" $^{40}$. De todo modo, a ausência da palavra "espinilho", aplicada à respectiva espécie vegetal (Vachellia caven), causa especial estranheza no texto de Balduíno Rambo, haja vista sua ampla, antiga e consagrada utilização no falar regional, bem como na literatura botânica da época, na região do Prata.

Esta confusão com nomes populares não justifica, todavia, a designação de "Parque Espinilho", dada por Rambo à singularidade vegetacional do sudoeste gaúcho. Mesmo assim,

39 A outra espécie citada por Rambo é o inhanduvá (Prosopis algarobilla, atual Prosopis affinis), por ele chamado de algarrobo.

40 Rambo, B., 1956. Op. cit., p. 130. não se pode desconhecer que o termo vingou na literatura botânica sul-rio-grandense, apesar do equívoco, e ganhou foro oficial com a criação do "Parque Estadual do Espinilho", anteriormente comentado.

Mais lógico seria designar a vegetação como Parque do Inhanduvá, posto ser esta a sua espécie mais característica (Figura 3), e não o espinilho, que tem ampla distribuição no Estado. Além disso, como assinalado por Marchiori et al. (1985b) ao proporem a mudança de nome, o inhanduvá é a "espécie a mais importante para a fisionomia e estrutura da vegetação" em foco, apresentando, ainda, "valores mais elevados de abundância, dominância e frequiência" ${ }^{41}$. Sobre este ponto, resta lembrar que as associações e formações vegetais, como visto anteriormente, são costumeiramente designadas com base na espécie dominante: Espinillar, associação de espinilhos; Ñandubaysal, de inhanduvá;

${ }^{41}$ Marchiori, J.N.C., et al., 1985b. Op. cit., p. 332. 
Algarrobal, de espécies de Prosopis (algarrobo e inhanduvá), etc.

$\mathrm{O}$ termo "Parque", aplicado às duas denominações $^{42}$, não merece reparos, uma vez que as árvores crescem, de fato, afastadas umas das outras ou formando agrupamentos de poucos indivíduos, e suas copas, isoladas ou com pouca interpenetração, além de paucifoliadas, permitem o desenvolvimento de um denso estrato herbáceo, inclusive ao pé das árvores. São, precisamente, características desta natureza que justificam a atribuição do nome "Parque" a vegetações semelhantes sob o ponto de vista fisionômico-estrutural em outras partes do mundo, notadamente em regiões tropicais e subtropicais.

No rebate à proposta de Marchiori et al. (1985b), Galvani (2003) afirma que o uso do termo "espinilho" para a vegetação em estudo (Parque do Espinilho), em vez referência ao "nome popular da espécie Acacia caven", prende-se a "alguns elementos da classificação fitogeográfica sul-americana" que, apesar de não considerados pelos referidos autores ${ }^{43}$, teriam sido "levados em conta por Rambo em sua referência ao local" 4 . Com estas palavras, Galvani quer dizer que o nome "espinilho" foi atribuído por Balduíno Rambo em "referência" ao "tipo de formação vegetal ocorrente na denominada Província do Espinhal"45. Este parecer, todavia, não resiste a uma análise mais aprofundada sob o enfoque etimológico, não segue a norma usual de designação fitogeográfica, além ter sido aplicado, pelo proponente (Balduíno Rambo), a associações amplamente reconhecidas na literatura como distintas.

Em primeiro lugar, embora derivadas de espino (espinho, em português), as palavras

42 Refere-se aos nomes "Parque do Espinilho" e "Parque de Inhanduvá”, propostos, respectivamente, por Rambo (1956) e Marchiori et al. (1985b).

43 Refere-se a Marchiori et al. (1985b), podendo, igualmente, referir-se a Marchiori (2004) e Marchiori et al. (1985a).

${ }^{44}$ Galvani, F.R., 2003. Op. cit., p. 42-43.

45 Galvani, F.R., 2003. Op. cit., p. 43. espinillo e espinal são vozes distintas na língua de Cervantes: a primeira, é o nome comum mais difundido para Vachellia caven, tanto na Argentina como no Uruguai ${ }^{46}$; a segunda, foi especialmente criada, por Cabrera $(1951)^{47}$, para designar uma das províncias do Domínio Chaquenho, justamente aquela na qual se insere a singularidade vegetacional de Barra do Quaraí.

O termo Espinillar, por sua vez, aplica-se a agrupamentos de espinillos (Vachellia caven). Freqüentes, sobretudo, na periferia de matas ciliares, os espinillares são muito conspícuos na paisagem da Mesopotâmia argentina e do oeste da República do Uruguai. Igualmente freqüentes no Rio Grande do Sul, tais associações são encontradas em diversas regiões fisiográficas do Estado, fato comprovado, até mesmo, na toponímia regional, caso de "Espinilho Grande", localidade do Planalto Médio.

Em português, as palavras espinilho e espinhal também se aplicam a entidades distintas. A primeira - um platinismo-, é nome comum para Vachellia caven, além de outras duas Leguminosas: Gleditsia amorphoides (mais conhecida por coronilha), e Vachellia farnesiana ${ }^{48}$. A palavra espinal, embora também dicionarizada, é um adjetivo de uso restrito à anatomia

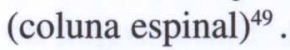

Sem correspondente em português, o termo espinillar pode ser traduzido como "parque de espinilho", uma vez que a vegetação é marcada

$46 \mathrm{Na}$ Argentina, a espécie Acacia caven recebe outros nomes populares além de Espinillo, dependendo da região: Churqui, Aromita, Espino, Caven (Ulibarri, E. Leguminosae, Leguminosas. In: Kiesling, R. (org.). Flora de San Juan, Republica Argentina. Buenos Aires: Vazquez Mazzini Editores, 1994. p. 260).

47 Desde 1951, Cabrera usa o termo "Espinal" para designar esta província do Domínio Chaquenho. O uso do termo foi novamente utilizado em 1971, em sua obra sobre Fitogeografia da Argentina, e em obra posterior (e mais ampla), feita com Willink (1973), para a América Latina.

48 Houaiss \& Villar, 2001. Op. cit., p. 1232.

49 Houaiss \& Villar, 2001. Op. cit., p. 1231. 
fisionômica e estruturalmente pela Vachellia caven (espinilho) e seus indivíduos distribuemse ao molde dos parques.

Não se pode esquecer, ainda, que tanto o inhanduvá, como o algarrobo, o quebracho, a cina cina, a taleira, a coronilha e as sombrasde-touro - principais árvores da vegetação em análise -, são todas armadas de espinhos, e não apenas o espinilho (Vachellia caven). A palavra espinal, atribuída por Angel L. Cabrera à província fitogeográfica, ela, sim, é uma denominação adequada (corresponde a "espinhal", em português, ou seja, vegetação cheia de espinhos), até mesmo por que não caberia um termo fitogeográfico de tão ampla abrangência ser designado com base no nome de uma única espécie. Na vegetação em foco, todavia, a espécie dominante e que se impõe, fisionomicamente, é o inhanduvá, motivo pelo qual o nome de Parque Espinilho não se mostra adequado.

Outro ponto merecedor de exame é o fato de que Balduíno Rambo não reservou a expressão "Parque Espinilho" para a associação de Prosopis e Acacia. Ao contrário: à página 144, ao tratar da descrição de uma viagem de Quaraí a Uruguaiana, lê-se, com clareza:

\begin{abstract}
"Na descida para o Quaraí-Mirim, o meláfiro chega a formar verdadeiras abas na orla das coxilhas, com miríadas de ágatas e pequenas drusas de quartzo, entre as quais rasteja a flora mais pobre que se possa imaginar. Nos campos das encostas, aparece pela primeira vez em escala apreciável o parque espinilho. Constituído na essência pelo inhanduvaí, não lhe faltam o branquilho, a sombra de touro e a cina-cina"50.
\end{abstract}

Como visto anteriormente, o inhanduvaí, para Rambo, não era outra espécie senão Acacia caven (atual Vachellia caven), o popular espinilho $^{51}$. De fato, no Quaraí-Mirim, em solos gerados a partir de rochas vulcânicas, ainda hoje se pode comprovar a descrição precisa quase fotográfica -, realizada por Rambo: o que ali se encontra, em verdade, é um espinillar, segundo a nomenclatura castelhana, ou um verdadeiro "Parque de Espinilho", em bom português, posto ser uma associação de indivíduos de Vachellia caven com a estrutura típica de parque, vegetação encontradiça em diversas regiões fisiográficas do Rio Grande do Sul (Figura 4).

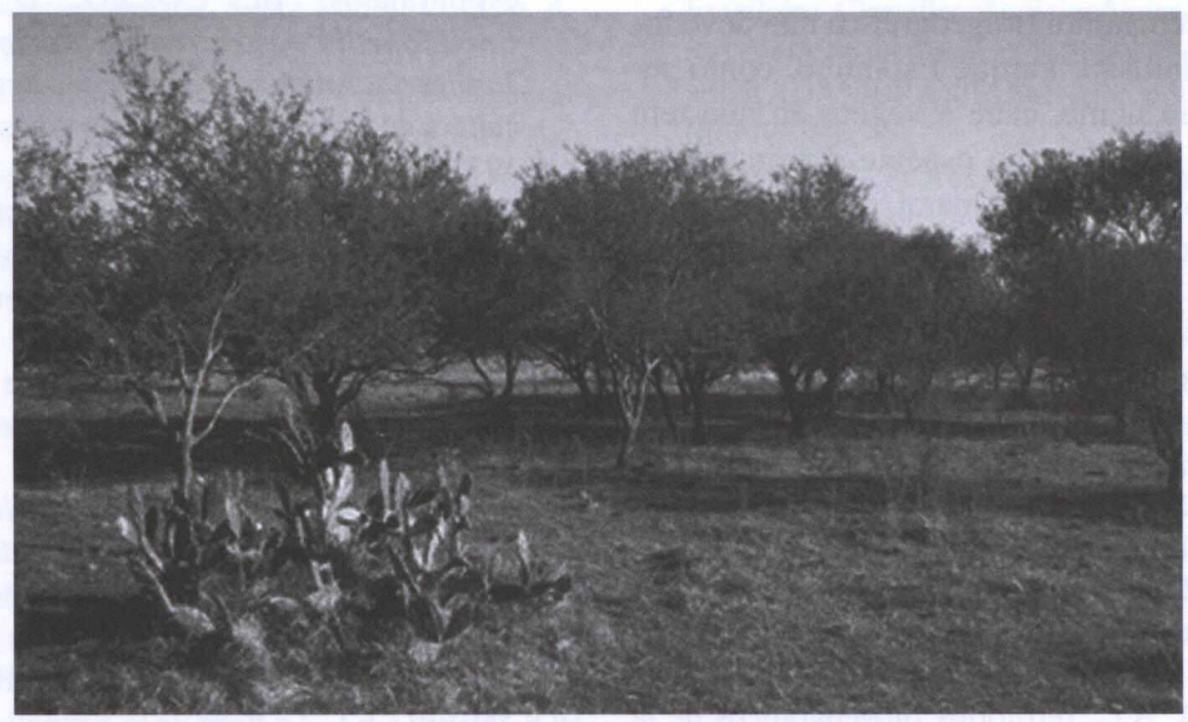

FIGURA 4 - Aspecto geral do Parque de Espinilho, composto, basicamente, por indivíduos de Vachellia caven, junto à mata ciliar do rio Quaraí Mirim (Quaraí, RS).

${ }^{50}$ Rambo, B., 1956. Op. cit. p. 144.

${ }^{51}$ Rambo, B., 1956. Op. cit., p. 130. (ver parágrafo “h”). 
Em outra passagem, página 131, o texto também deixa implícito que Balduíno Rambo não reservou o termo Parque Espinilho para a associação de Prosopis e Acacia:

"O aspecto do parque espinilho, em que domina o algarrobo, é tão estranho que custa considerálo como legítima formação brasileira".

A frase acima é reveladora: para Rambo também haviam parques de espinilho sem algarrobo (leia-se Prosopis albarobilla, atual Prosopis affinis) e com outra espécie dominante, caso da vegetação descrita para o Quaraí-Mirim, anteriormente comentada.

Posto que o termo fitogeográfico em discussão foi originalmente utilizado por Balduíno Rambo tanto para o Ñandubaysal de Barra do Quaraí, como para o Espinillar do Quaraí-Mirim, cabe perguntar-se qual das duas vegetações merece, efetivamente, a designação em debate. Elas são suficientemente distintas em sua composição, apesar de ambas estarem vinculadas ao mesmo distrito (del Ñandubay) e província fitogeográfica (del Espinal), como ensina Angel Lulio Cabrera.

A nomenclatura fitogeográfica não deve fomentar confusão: Parque Espinilho, como sugerido pelo nome, cabe à vegetação que tem Vachellia caven como espécie dominante. À vegetação de Barra do Quaraí, por conseguinte, convém a denominação de Parque de Inhanduvá.

\section{REFERÊNCIAS BIBLIOGRÁFICAS}

ASCASUBI, H. Santos Vega el payador. In: Poesia gauchesca. México: Fondo de Cultura Económica, 1984. v. 1. p. 304-624.

BILONI, J.S. Arboles autoctonos argentinos. Buenos Aires: Tipográfica Editora Argentina, 1990. 335 p.

BURKART, A. Ojeada sinóptica sobre la vegetación del Delta del Río Paraná. Darwiniana, San Isidro, v. 11, n. 3, p. 457-561, 1957.

CABRERA, A.L. Territórios fitogeográficos de la Republica Argentina. Boletín de la Sociedad Argentina de Botánica, v. 4, n. 1-2, p. 21-65, 1951.
CABRERA, A.L. Fitogeografia de la Republica Argentina. Boletín de la Sociedad Argentina de Botánica, Buenos Aires, v. 14, n. 1-2, p. 1-42, 1971 (separata).

CABRERA, A.L. Territorios fitogeograficos de la Republica Argentina. In: KUGLER, W.F. (org.). Enciclopedia Argentina de Agricultura $y$ Jardineria. Buenos Aires: ACME, 1994. v. 2. p. 1-85.

CABRERA, A.L.; WILLINK, A. Biogeografia de America Latina. Washington: Secretaria General de la Organización de los Estados Americanos (OEA), 1973. 117 p.

CHEBATAROFF, J. La vegetación del algarrobal, monte espinoso del litoral. I. Divisiones de la Província Fitogeográfica Uruguayense. Resúmenes Jornadas de Ciencias Naturales I, Montevideo, 1980a. p. 77-78.

CHEBATAROFF, J. La vegetación del algarrobal, monte espinoso del litoral. II. Componentes principales del algarrobal. Resúmenes Jornadas de Ciencias Naturales I, Montevideo, 1980b. p. 79-80.

DEMAIO, P.; KARLIN, U.O.; MEDINA, M. Árboles nativos del centro de Argentina. Buenos Aires: L.O.L.A., 2002. 210 p.

DIMITRI, M.J. Las areas argentinas de bosques espontáneos. In: COZZO, D. (org.). Enciclopedia Argentina de Agricultura y Jardinería. Arboles forestales, maderas y silvicultura de la Argentina. Buenos Aires: ACME, 1979. v. 2. p. 6-17.

DREYS, N. Noticia descriptiva da Provincia do RioGrande de S. Pedro do Sul. Rio de Janeiro: Typ. Imp. e Const. de J. Villeneuve e Comp., 1839. $216 \mathrm{p}$.

FRENGUELLI, J. Rasgos principales de Fitogeografia argentina. Revista del Museo de la Plata, Botánica, v. 3, p. 65-181, 1941.

GALVANI, F.R. Vegetação e aspectos ecológicos do Parque Estadual do Espinilho, Barra do Quarai, RS. 132 p. Porto Alegre: Universidade Federal do Rio Grande do Sul, 2003. Tese de Doutorado (Programa de Pós-Graduação em Botânica).

HOLMBERG, E.L. La flora de la Republica Argentina. Segundo Censo Republica Argentina, 1895, v 1, p. 385-474, 1898. 
HOUAISS, A.; VILLAR, M. de S. Dicionário Houaiss da Língua Portuguesa. Rio de Janeiro: Objetiva, 2001. 2922 p.

LEITE, P.F. As diferentes unidades fitoecológicas da região sul do Brasil. Proposta de classificação. Curitiba: Universidade Federal do Paraná, 1994. 160 p. Dissertação de Mestrado (Curso de PósGraduação em Engenharia Florestal).

LEITE, P.F. As diferentes unidades fitoecológicas da região sul do Brasil. Proposta de classificação. Cadernos de Geociências, Rio de Janeiro, n. 15, p. 73-164, 1995.

MARCHIORI, J.N.C. Fitogeografia do Rio Grande do Sul: Campos sulinos. Porto Alegre: EST Edições, 2004. 110 p.

MARCHIORI, J.N.C.; LONGHI, S.J.; GALVÃO, L. O gênero Prosopis L. (Leguminosae Mimosoideae) no Rio Grande do Sul. Ciência $e$ Natura, Santa Maria, n. 5, p. 171-177, 1983.

MARCHIORI, J.N.C.; LONGHI, S.J. Estrutura fitossociológica de uma associação natural de Parque Inhanduvá com quebracho e cina-cina, no Rio Grande do Sul. Ciência e Natura, Santa Maria, n. 7, p. 147-162, 1985a.

MARCHIORI, J.N.C.; LONGHI, S.J.; GALVÃO, L. Composição florística e estrutura do Parque de Inhanduvá no Rio Grande do Sul. Rev. Centro de Ciências Rurais, Santa Maria, v. 15, n. 4, p. 319-334, 1985b.

MUTARELLI, E.J. Riqueza de los bosques espontâneos. In: COZZO, D. (org.). Enciclopedia Argentina de Agricultura y Jardineria. Arboles forestales, maderas y silvicultura de la Argentina. Buenos Aires: ACME, 1979. v. 2. p. 18-33.
PARODI, L.R. Las regiones geográficas argentinas. In: VERDOORN, J. (ed.). Plants and plant science in Latin América. Waltham: Chronica Botanica Company, 1945. p. 127-132.

PAZ, E.A.; BASSAGODA, M.J. Aspectos fitogeográficos y diversidad biológica de las formaciones boscosas del Uruguay. Ciência \& Ambiente, Santa Maria, n. 24, p. 35-50, 2002.

RAMBO, B. A fisionomia do Rio Grande. Viagens de estudo. Porto Alegre: Typografia do Centro, 1938. 54 p.

RAMBO, B. A fisionomia do Rio Grande do Sul. Porto Alegre: Livraria Selbach, 1956. 456 p.

REITZ, R.; KLEIN, R.M.; REIS, A. Projeto Madeira do Rio Grande do Sul. Sellowia, Itajaí, n. 3435, p. 1-525, 1983.

SEYMOUR, R.A. Un poblador de las Pampas. Córdoba: Impressos M.C., 1995. 325 p.

SIMÕES LOPES NETO, J. Contos gauchescos $e$ Lendas do Sul. Porto Alegre: Editora Globo, 1957. $438 \mathrm{p}$.

TORTORELLI, L.A. Maderas y bosques argentinos. Buenos Aires: ACME, 1956. 910 p.

ULIBARRI, E. Leguminosae, Leguminosas. In: KIESLING, R. Flora de San Juan. Republica Argentina. Buenos Aires: Vazquez Mazzini Editores, 1994. p. 257-332.

VELOSO, H.P.; GÓES-FILHO, L. Fitogeografia brasileira. Classificação fisionômico-ecológica da vegetação neotropical. Boletim Técnico, Projeto RADAMBRASIL, Salvador, p. 1-80, 1982. (Sér. Vegetação).

WAECHTER, J.L. Padrões geográficos na flora atual do Rio Grande do Sul. Ciência \& Ambiente, Santa Maria, n. 24, p. 93-108, 2002. 